\title{
DnaJ/hsp40 chaperone domain of SV40 large $T$ antigen promotes efficient viral DNA replication
}

\author{
Kathryn S. Campbell, ${ }^{1,5}$ Karen P. Mullane, ${ }^{2,5}$ Ibrahim A. Aksoy, ${ }^{1}$ Hilde Stubdal, ${ }^{3}$ Juan Zalvide, ${ }^{3}$ \\ James M. Pipas, ${ }^{4}$ Pamela A. Silver, ${ }^{1}$ Thomas M. Roberts, ${ }^{1,6}$ Brian S. Schaffhausen, ${ }^{2}$ and \\ James A. DeCaprio ${ }^{3}$ \\ ${ }^{1}$ Department of Cancer Biology, Dana Farber Cancer Institute and Department of Pathology, Harvard Medical School, \\ Boston, Massachusetts 02115 USA; ${ }^{2}$ Department of Biochemistry, Tufts University School of Medicine, Boston, \\ Massachusetts 02111 USA; $^{3}$ Department of Adult Oncology, Dana Farber Cancer Institute and Department of Medicine, \\ Harvard Medical School, Boston, Massachusetts 02115 USA; and ${ }^{4}$ Department of Biological Sciences, University of \\ Pittsburgh, Pittsburgh, Pennsylvania 15260 USA
}

The amino-terminal domain of SV40 large tumor antigen (TAg) is required for efficient viral DNA replication. However, the biochemical activity associated with this domain has remained obscure. We show here that the amino-terminal domain of TAg shares functional homology with the J-domain of DnaJ/hsp40 molecular chaperones. DnaJ proteins function as cofactors by regulating the activity of a member of the 70-kD heat shock protein family. Genetic analyses demonstrated that amino-terminal sequences of TAg comprise a novel J-domain that mediates a specific interaction with the constitutively expressed hsc70 and show that the J-domain is also required for efficient viral DNA replication in vivo. Furthermore, we demonstrated that the J-domain of two human DnaJ homologs, HSJ1 or DNAJ2, could substitute functionally for the amino-terminus of TAg in promoting viral DNA replication. Together, our findings suggest that TAg uses its J-domain to support SV40 DNA replication in a manner that is strikingly similar to the use of Escherichia coli DnaJ by bacteriophage $\lambda$ in DNA replication. However, TAg has evolved a more efficient strategy of DNA replication through an intrinsic J-domain to associate directly with a partner chaperone protein. Our observations provide evidence of a role for chaperone proteins in the process of eukaryotic DNA replication.

[Key Words: SV40 virus; large T antigen; DnaJ; Hsc70; chaperone; J-domain]

Received December 18, 1996; revised version accepted March 20, 1997.

The large tumor antigen (TAg) of the DNA tumor virus SV40 has been the focus of intense study for the past four decades because of its ability to usurp normal cellular processes. What has emerged from this research is that TAg carries out multiple biological functions, at least in part through specific associations with cellular proteins. The identification and elucidation of the normal cellular functioning of these proteins has advanced our understanding of the molecular mechanisms of DNA replication, cell cycle regulation, and neoplastic transformation. For these reasons TAg has proven to be an invaluable tool for investigating basic cellular processes.

TAg plays an essential role in both viral replication in permissive monkey cells and transformation of cultured rodent cells. Genetic analyses indicate that these functions can be ascribed to discrete colinear domains of $\mathrm{TAg}$. The replication activities intrinsic to $\mathrm{TAg}$ are as-

\footnotetext{
${ }^{5}$ These authors contributed equally to this work.

${ }^{6}$ Corresponding author.

E-MAIL thomas_roberts@dfci.harvard.edu; FAX (617) 632-4770
}

sociated with the following domains: ATPase (amino acids 418-627) (Clark et al. 1981; Manos and Gluzman 1985; Wiekowski et al. 1987; Bradley 1990), helicase (amino acids 126-627) (Stahl et al. 1986), and origin binding (amino acids 132-246) (Gluzman and Ahrens 1982; Kalderon and Smith 1984; Stillman et al. 1985; Cole et al. 1986; Paucha et al. 1986; Simmons 1986; Gish and Botchan 1987; Arthur et al. 1988). Although TAg is the sole viral protein necessary for SV40 viral DNA replication, association with several host replication proteins such as replication protein A (RPA) (Collins and Kelly 1991; Melendy and Stillman 1993) and DNA polymerase $\alpha$ (Smale and Tjian 1986; Dornreiter et al. 1992) are also necessary. TAg possesses two binding sites for cellular growth-suppressing proteins that are required for its transformation function. The LXCXE motif (amino acids 103-107) of TAg mediates binding to the cell cycle-regulated retinoblastoma $(\mathrm{pRb})$ protein and the pRb-related proteins p130 and pl07 (DeCaprio et al. 1988; Ewen et al. 1989; Zalvide and DeCaprio 1995) and a carboxy-terminal domain (amino acids 273-517) is required for asso- 
ciation with p53 (Schmieg and Simmons 1988; Kierstead and Tevethia 1993).

An additional domain residing at the amino terminus (residues 1-82) is necessary for TAg function. In addition to a role in both viral DNA replication and transformation (Gluzman and Ahrens 1982; Pipas et al. 1983; Srinivasan et al. 1989; Montano et al. 1990; Thompson et al. 1990; Marsilio et al. 1991; Maulbecker et al. 1992; Peden and Pipas 1992; Zhu et al. 1992; Symonds et al. 1993; Quartin et al. 1994; Weisshart et al. 1996), the aminoterminal domain is important for transcriptional regulation, hexamer assembly, virion production, TAg stability, stimulating cellular DNA synthesis, and ability to associate with the TATA-binding protein (TBP) (Peden et al. 1990; Marsilio et al. 1991; Zhu et al. 1991; Gruda et al. 1993; Dickmanns et al. 1994; Weisshart et al. 1996). Recently, Stubdal et al. (1996) have reported that the amino terminus was necessary for altering the phosphorylation state of pRb-related proteins p130 and p107. Despite this extensive list of activities that contribute to the viral life cycle, the biochemical activity associated with the amino-terminal domain has remained unclear.

A clue to how the amino-terminal domain of TAg may contribute to these activities has come from the study of a family of molecular chaperones known as DnaJ or hsp40 proteins. DnaJ proteins are members of a highly conserved class of molecular chaperones; homologs have been isolated from organisms as diverse as Escherichia coli, yeast, and human. All DnaJ family members contain a conserved domain required for their ability to function. It is the presence of this domain, commonly referred to as the J-domain, that defines membership in the DnaJ family (Silver and Way 1993). It was postulated that amino-terminal residues of polyomavirus tumor antigens, including SV40 TAg, share some sequence homology with the J-domain of DnaJ chaperones (Cheetham et al. 1992; Kelley and Landry 1994). The $\mathrm{J}$-domain, which is required for DnaJ cofactor function, is proposed to be the interaction site for members of the $70-\mathrm{kD}$ heat shock protein family (hsp70) (Silver and Way 1993).

hsp70 proteins are highly conserved ATP-binding proteins present in all cell types and distributed throughout all cellular compartments (Gething and Sambrook 1992; Georgopoulos and Welch 1993; Hartl 1996). hsp70 and DnaJ function together in a complex to carry out a variety of biochemical activities including nascent protein folding, protein translocation across the endoplasmic reticulum or mitochondrial membranes, prevention of protein aggregation, regulation of protein conformation, and proteolysis of abnormal proteins (Gething and Sambrook 1992; Georgopoulos and Welch 1993; Hartl 1996). More recently, molecular chaperones have been implicated in transcriptional regulation, signaling, phosphorylation, and degradation of short-lived proteins (Rutherford and Zucker 1994; Yaglom et al. 1996). A DnaJ/hsp70 complex is also known to regulate the remodeling of multiprotein complexes. One well characterized example is the process of bacteriophage $\lambda$ DNA replication (Alfano and McMacken 1989; Zylicz et al. 1989). In this study we find that the amino-terminal sequences of TAg comprise a novel J-domain that governs a specific interaction with the constitutively expressed hsp70 family member hsc 70, and plays a critical role in viral DNA replication in vivo. These data suggest that the J-domain supports SV40 DNA replication in a manner that may be analogous to the use of $E$. coli Dnal by bacteriophage $\lambda$ in $\lambda$ DNA replication.

\section{Results}

Expression of mutants with lesions in the DnaI homology region of $\mathrm{TAg}$

In an effort to determine whether TAg amino-terminal sequences share functional homology to DnaJ chaperones, we carried out a genetic analysis. We chose to mutate several residues that are highly conserved and known to be important for DnaJ chaperone activity in other systems. As a guideline for mutagenesis, we generated an alignment of the amino-terminal residues of polyomavirus tumor antigens and the $\sim 70$ amino acid J-domain from several DnaJ homologs (Fig. 1). Comparison of the sequences indicates that several residues are absolutely conserved between DnaJ proteins and tumor antigens. The sequence $\mathrm{HPDK} / \mathrm{R}$ is invariant in the $\mathrm{J}$ domains of DnaJ proteins and is present in all polyomavirus tumor antigens (residues 42-45 in SV40 TAg). Nuclear magnetic resonance (NMR) secondary structure determination of the J-domain of E. coli DnaJ and human hsp 40 (HDJ-1) indicates that the HPDK/R motif forms a loop between two $\alpha$-helices (Szyperski et al. 1994; Hill et al. 1995; Pellecchia et al. 1996; Qian et al. 1996). A computer-based analysis of TAg secondary structure predicts that this motif may exist in a similar exposed region (Fig. 1 ). Biochemical and genetic studies of $E$. coli and yeast DnaJ homologs indicate that the HPDK/R motif is critical for DnaJ function (Feldheim et al. 1992; Wall et al. 1994, 1995; Tsai and Douglas 1996). These analyses further define a region (HPDK/R motif) within the J-domain referred to here as the J-box. Because the J-domain of DnaJ proteins is thought to be important for mediating a specific interaction with an hsp70 protein (Silver and Way 1993), we suspected that J-domain-like sequences of TAg could be required to recruit a cochaperone. It was reported previously that TAg associates with the constitutive hsp70 family member hsc70 /Sawai and Butel 1989), although the biological significance of a TAg/ hsc70 complex was unclear. Given the requirement of the J-domain for DnaJ activity, we hypothesized that amino-terminal sequences of TAg share functional homology with DnaJ chaperones and that a J-domain-associated activity may be required for SV40 DNA replication. To address this possibility, we constructed a series of single amino acid substitutions of conserved aminoterminal residues of $\mathrm{TAg}$ (H42Q, P43S/T57I, P43F, D44N, K45Q, and G47E) and assayed hsc70 binding and viral DNA replication.

\section{Genetic analysis of $\mathrm{TAg} / \mathrm{hsc} 70$ complex formation}

As a first step in analyzing the role of the J-box motif in 

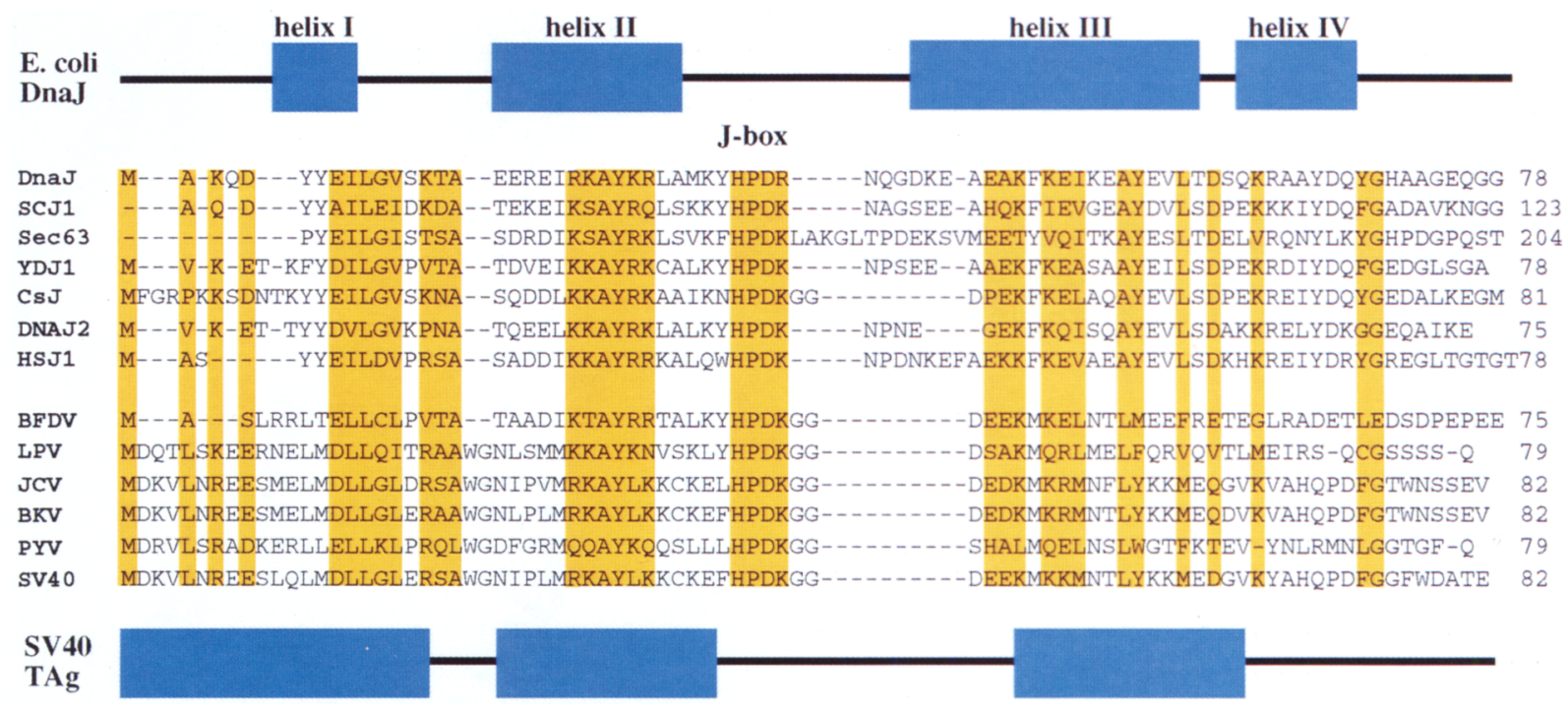

Figure 1. SV40 TAg shares sequence homology with DnaJ molecular chaperones. Alignment of the J-domain from various DnaJ homologs and the amino-terminal residues of several polyomavirus TAgs: budgerigar fledgling disease virus (BFDV); lymphotropic polyomavirus (LPV); human JC polyomavirus (JCV); human BK polyomavirus (BKV); murine polyomavirus (PYV); and simian virus 40 (SV40). DnaJ homologs from E. coli (DnaJ), yeast (SCJ1, Sec63, YDJ1), cucumber (CsJ), and human (DNAJ2 and HSJ1) are depicted. The alignment was maximized by introducing gaps marked by dashes. The prototypical DnaJ homolog from $E$. coli is positioned first, and the domain structure of the J-domain of E. coli DnaJ as determined by NMR studies is depicted above (Szyperski et al. 1994; Hill et al. 1995; Pellecchia et al. 1996). The predicted structure of TAg J-domain was generated by the DNASTAR program Protean using the Chou-Fasman secondary structure prediction method. Helices are indicated by blue colored boxes and solvent exposed regions or loops are represented by black lines. Highly conserved residues are highlighted in yellow. Note the conserved HPDK/R motif, which is referred to as the J-box in this study.

TAg function, we generated BSC 40 monkey kidney cell lines and BALB/c 3T3 mouse embryo cell lines expressing either wild-type or mutant genomic TAg species. Each mutant was expressed stably as assayed by immunoblotting with an anti-TAg monoclonal antibody PAb419 (data not shown). Furthermore, mutations within the J-domain do not appear to affect nuclear localization (Peden and Pipas 1992 and data not shown).

We used these cell lines to compare directly the ability of wild-type or mutant TAgs to associate with members of the $70-\mathrm{kD}$ heat shock protein family (Fig. 2). As shown in Figure 2, A and B, wild-type TAg expressed in either BSC 40 cells or BALB/c 3T3 cells coprecipitated a band that reacted with an anti-hsc70/hsp70 antibody N27. In contrast, the TAg species encoded by J-domain mutants H42Q, P43S/T57I, P43F, D44N, K45Q, and G47E each failed to coprecipitate hsc70 (Fig. 2A,B). No specific immunoreactive band was seen in an anti-TAg antibody immunoprecipitate from cells expressing the vector control (Fig. 2 A,B). Anti-TAg (PAb101) immunoblots of the same membrane demonstrated that there was no significant difference in the level of TAg in each lane (Fig. 2A,B, bottom).

To determine whether the $70-\mathrm{kD}$ heat shock protein associated with wild-type TAg represents the constitutive (hsc70) or inducible (hsp70) family member, we per-
A

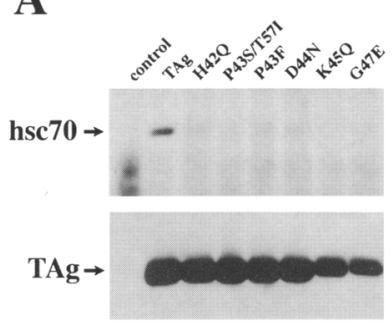

B

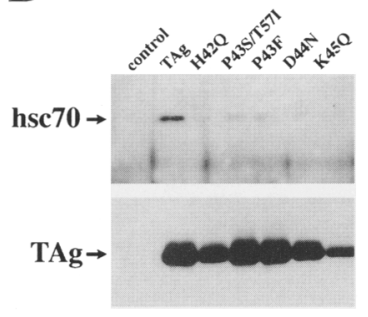

C

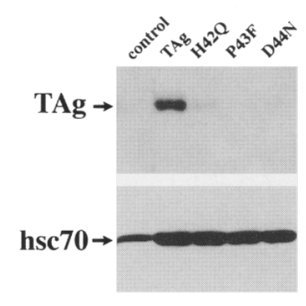

Figure 2. An intact J-domain is required for hsc70 binding. $(A)$ Extracts of TAg expressing BSC 40 cells or $(B)$ BALB/c $3 \mathrm{~T} 3$ cells stably expressing the indicated $\mathrm{TAg}$ species were immunoprecipitated with anti-TAg antibody (PAb101) and immunoblotted with anti-hsc70/hsp70 antibody (N27). Expression of TAg (bottom) was detected by immunoblotting the identical membrane with PAb101. Stripping and reprobing the membrane with a polyclonal antibody that reacts specifically with anti-hsc70 indicated that the immunoreactive band $($ top $)$ is hsc70 (data not shown). (C) Extracts of TAg expressing BALB/c 3T3 cells stably expressing the indicated TAg species were immunoprecipitated with an anti-hsc70 rat monoclonal antibody IB5 (Stressgen) and immunoblotted with PAb101. The levels of hsc70 in each lane was detected by immunoblotting the identical membrane with IB5. The positions of hsc70 and TAg are indicated. 
formed coimmunoprecipitation experiments with extracts prepared from BALB/c 3T3 cells stably expressing the TAg variants. Cell extracts were immunoprecipitated with an hsc70-specific rat monoclonal antibody (IB5) and assayed for the presence of TAg. Immunoblot analysis revealed that hsc70 stably associates with wildtype $\mathrm{TAg}$, but not with J-box mutants $\mathrm{H} 42 \mathrm{Q}, \mathrm{P} 43 \mathrm{~F}$, or D44N (Fig. 2C). To investigate whether an interaction between the inducible heat shock protein family member (hsp70) and TAg could be detected, we prepared extracts from the various TAg-expressing BALB/c 3T3 and BSC 40 cells. For these studies, cells were grown either under normal conditions $\left(37^{\circ} \mathrm{C}\right)$ or shifted to $42^{\circ} \mathrm{C}$ for 4 $\mathrm{hr}$ to induce the expression of hsp70. By immunoblot analysis with an anti-hsp70-specific antibody (C92), neither TAg nor the J-domain mutants were found to coimmunoprecipitate hsp70 (data not shown).

It was reported previously that small deletions in and around the HPDK motif affect TAg stability negatively (Marsilio et al. 1991). When we performed pulse-chase experiments on mutants $\mathrm{H} 42 \mathrm{Q}$ and $\mathrm{D} 44 \mathrm{~N}$, protein stability was identical to that seen with wild-type TAg (data not shown). Furthermore, J-domain mutants associated stably with pRb family members, p53, and DNA polymerase $\alpha$ (data not shown). Taken together, these results demonstrate that the J-box (HPDK/R motif) confers the ability of TAg to form a specific association with hsc70, the constitutively expressed member of the $70-\mathrm{kD}$ heat shock protein family.

The I-domain homology region of TAg is necessary for efficient DNA replication in $C V-1 P$ cells

Given that the amino terminus of TAg is required for SV40 DNA replication, we reasoned that a specific Jdomain-associated activity may be involved. Monkey kidney cells (CV-1P) permissive for replication of SV40 were cotransfected with pRSV-BneoT plasmids expressing genomic TAg or J-box mutants and an SV40-ori containing plasmid pSV01 $\triangle \mathrm{EP}$. At $48 \mathrm{hr}$ post-transfection, lysates were prepared and assayed for TAg expression by immunoprecipitation and immunoblotting with PAb101. As can be seen in Figure 3 (lower), TAg was expressed at approximately equal levels. In parallel, we transfected duplicate plates with identical plasmids and assayed DNA replication by Southern blot analysis.

The recovered replicated DNA is represented by the appearance of a $2790 \mathrm{bp}$ fragment from pSV01 $\Delta \mathrm{EP}$ that was resistant to digestion with $D p n I$ and hybridized to a ${ }^{32}$ P-labeled probe containing SV40-ori DNA (Fig. 3, middle). Quantitation of the autoradiogram is depicted as a bar graph (top) where replicated SV40-ori DNA is expressed in relative (PhosphorImager) units. Each bar represents the average amount of replicated DNA from the duplicate samples shown in the Southern blot (middle). Southern blot analysis revealed that $\mathrm{TAg}$ stimulated viral DNA replication in CV-1P cells, whereas mutations within the J-box led to a significant reduction in replication of a SV40-ori-containing plasmid (Fig. 3). TAg variants containing amino acid substi- tutions H42Q, P43S/T57I, P43F, D44N, K45Q, and G47E replicated at rates clearly lower (3- to 10-fold) than those stimulated by wild-type TAg (Fig. 3, top). In the absence of $\mathrm{TAg}$, no replication was detected (Figure 3, see control). These results extend previous genetic studies indicating that amino-terminal residues are required for $\mathrm{TAg}$ mediated DNA replication /Gluzman and Ahrens 1982; Pipas et al. 1983; Marsilio et al. 1991; Maulbecker et al. 1992; Peden and Pipas 1992; Weisshart et al. 1996), and point to a striking correlation between hsc70 binding and DNA replication. Notably, TAg mutant $\mathrm{H} 42 \mathrm{Q}$, which was defective for hsc70 binding and impaired for viral DNA replication, is analogous to the E. coli DnaJ mutant [DnaJ259(H33Q)] that blocks bacteriophage $\lambda$ replication and is defective for binding DnaK (E. coli hsp70 homolog) (Wall et al. 1994, 1995). Together, these data suggest that SV40 DNA replication may be similar to that of bacteriophage $\lambda$ where a complex assembled at the $\lambda$-ori between $E$. coli proteins DnaJ and DnaK, together with $\lambda$ proteins, is required for $\lambda$ replication.

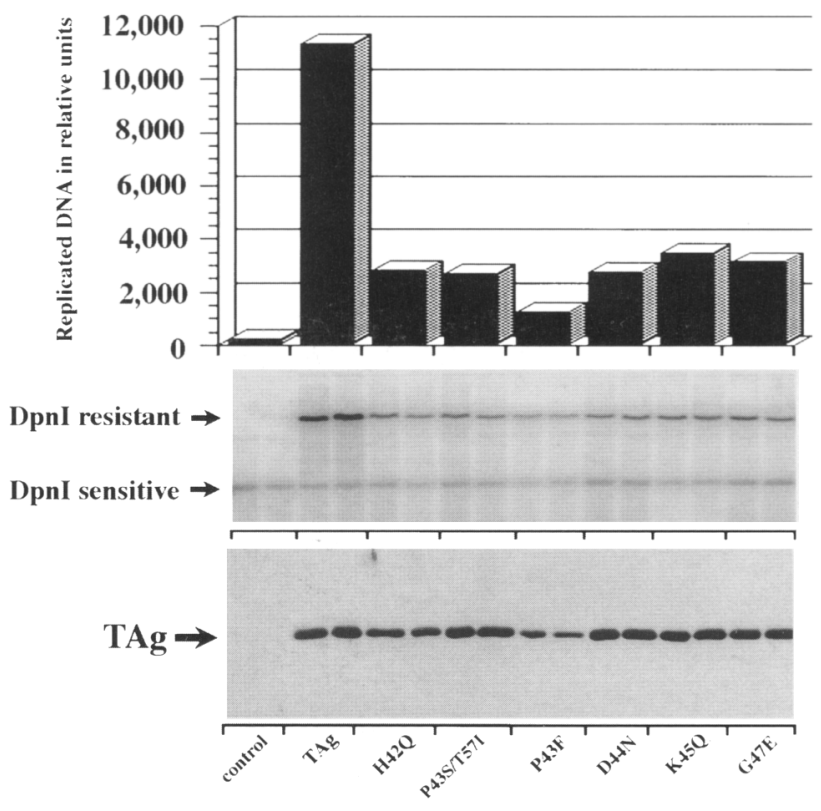

Figure 3. An intact J-domain is necessary for promoting efficient DNA replication. CV-1P cells were transfected in quadruplicate with the indicated TAg genomic constructs and an SV40-ori-containing plasmid pSV01 $\Delta E$ P. Duplicate Hirt extracts were prepared from cells and subjected to Southern blot analysis (middle). The positions of replicated DNA (DpnI-resistant fragment) and unreplicated DNA ( $D p n I-$ sensitive fragment) are indicated in the representative experiment shown. Quantitation of the Southern blot (middle) was performed using a Molecular Dynamics PhosporImager (top). The bar graph represents replicated DNA in relative (PhosphorImager) units and is based on the average amount of replicated SV40-ori-containing DNA of duplicate samples (middle). TAg protein expression of the indicated TAg variants was detected by immunoprecipitation and immunoblot analysis with anti-TAg antibody PAbl01 (bottom). The position of TAg is indicated. Duplicate samples are bracketed and denoted below by name. 
Given that the DpnI-resistant DNA isolated $48 \mathrm{hr}$ following transfection likely represents an accumulation of replicated product, we wanted to determine whether the J-domain-dependent effect on the stimulation of DNA replication varied at different times post-transfection. To address this question, we performed a viral DNA replication assay similar to that described above. CV1-P cells were cotransfected with pCMV-based vectors containing the various cDNA TAg variants indicated and a SV40ori-containing plasmid pSV01 $\triangle E P$. For the time-course experiment, lysates were prepared 14,38 , and $62 \mathrm{hr}$ posttransfection and assayed for TAg expression by immunoprecipitation and immunoblotting with PAbl01. As can be seen in Figure 4 (lower), the TAg variants were expressed at more or less equivalent levels. The expression of TAg, H42Q, and D44N was consistently low at the 14-hr time point. In parallel, we assayed DNA replication by Southern blot analysis.

The results of the DNA replication assay indicate that at $14 \mathrm{hr}$ post-transfection the level of $D p n I$-resistant replicated DNA isolated from cells expressing TAg mutants $\mathrm{H} 42 \mathrm{Q}$ and $\mathrm{D} 44 \mathrm{~N}$ was indistinguishable from that found from cells expressing the vector control (Fig. 4, middle). In contrast, although the levels of replicated DNA were low at the 14-hr timepoint, expression of wild-type TAg resulted in a significant increase in the amount of DpnIresistant product when compared to expression of either the vector control or the J-domain mutants. Quantitation of the Southern blot indicates that at $14 \mathrm{hr}$ following transfection, wild-type TAg stimulated DNA replication at levels that appear to be $\geqslant 30$-fold higher than either of the J-domain mutants (Fig. 4, top). However, because the amount of replicated DNA isolated from J-domain mutants was near background, it is difficult to determine the actual fold increase in stimulation of DNA replication for wild-type TAg relative to the mutants. When assayed at both $38 \mathrm{hr}$ and $64 \mathrm{hr}$ post-transfection, the amount of accumulated DpnI-resistant DNA from cells transfected with wild-type $\mathrm{TAg}$ was $\sim 15$-fold greater than that observed for J-domain mutants $\mathrm{H} 42 \mathrm{Q}$ and D44N (Fig. 4, top). These data suggest that the J-domain dependent effect on DNA replication at early times posttransfection is considerable, and is possibly much greater than the effects observed at 38, 48, and $62 \mathrm{hr}$. Upon analysis of several separate DNA replication assays, we noticed some variability in both the amount of replicated DNA and in the extent of stimulation of DNA replication by wild-type $\mathrm{TAg}$ (3- to 20 -fold) relative to J-domain mutants (cf. Fig. 3 with Fig. 4). However, over the course of 11 independent experiments, in which both wild-type TAg and mutant $\mathrm{H} 42 \mathrm{Q}$ were assayed at 42-48 hr post-transfection, wild-type TAg stimulated DNA replication at levels $7.3 \pm 3.2$-fold greater than observed for $\mathrm{H} 42 \mathrm{Q}$.

\section{Chimeric TAgs form a stable complex with hsc70}

The data in Figures 3 and 4 demonstrate that residues within the conserved J-box of TAg are required for TAgmediated DNA replication. Because the amino-terminal mutants assayed here result in a loss of function, we cannot rule out the possibility that we have disrupted a function that is unrelated to the J-domain homology. Therefore, as a further test of the contention that the
Figure 4. Time course of viral DNA replication. CV-1P cells were transfected with the indicated TAg cDNA constructs or vector control and an SV40-ori containing plasmid, pSV01 $\Delta E P$. Cellular extracts were prepared and processed at 14, 38, and $62 \mathrm{hr}$ post-transfection for either DNA replication assay or TAg expression assay as described in Fig. 3. In the representative experiment shown, TAg variants were expressed at approximately equal levels as assayed by immunoprecipitation and immunoblot analysis with anti-TAg antibody PAblo1 (bottom). The position of TAg is indicated. Replicated DNA is depicted in the Southern blot where the positions of replicated DNA (DpnI-resistant fragment) and unreplicated DNA (DpnIsensitive fragment) are indicated (middle). Quantitation of the Southern blot is shown as a bar graph (top). The vertical axis on the left indicates the relative units $(0-500)$ for the 14 -hr time point. The vertical axis on the right corresponds to the relative units $(0-20,000)$ for the 38 -hr and 62 -hr time points. Extracts from cells transfected with vector control were prepared at the $62 \mathrm{hr}$ time point. The bar graph represents replicated DNA in relative (PhosphorImager) units and is based on the average amount of replicated SV40-ori-containing DNA of duplicate samples (middle). Duplicate samples are bracketed and denoted below by name. 
amino terminus of TAg is a bona fide J-domain, and that the effects on DNA replication are a function of the Jdomain, we constructed two chimeric TAgs (H. Stubdal, J. Zalvide, K.S. Campbell, C. Schweitzer, T.M. Roberts, and J.A. DeCaprio, in prep.). The amino-terminal 82 residues of TAg were substituted with the J-domain from two different authentic human DnaJ homologs, HSJ1 (Cheetham et al. 1992) or DNAJ2 (Oh et al. 1993) (see Fig. 1 for sequence homology). To determine whether DNA replication was specific to the J-domain, the conserved histidine residue in the J-box was mutated to glutamine (HQ) in each chimeric TAg.

We first assayed for the ability of the chimeric TAgs to associate with human hsc70 in a transient transfection assay. Human osteosarcoma (U2OS) cells were cotransfected with a vector that expresses myc epitope-tagged human hsc70 cDNA, to distinguish it from the endogenous protein and $\mathrm{pCMV}$-based vectors containing the cDNA TAg species indicated (Fig. 5A). The transfected $\mathrm{TAg}$ species were immunoprecipitated with anti-TAg antibody (PAb101) and immunoblotted with a monoclonal antibody that is specific to the myc epitope tag (9E10). In agreement with results shown in Figure 2 with mouse and monkey cells expressing $\mathrm{TAg}$, wild-type $\mathrm{TAg}$ associated with tagged human hsc70 (Fig. 5A, lanes 2,7), whereas mutant H42Q was impaired (Fig. 5A, lane 3). Furthermore, a deletion of residues that comprise the entire J-domain homology region of TAg (residues 1-82), abolished binding to tagged human hsc70 (see mutant T83-708, Fig. 5A, lane 10). When chimeric TAgs were examined, anti-TAg antibody coprecipitated hsc70 from cells expressing the chimeric TAgs HSJ1-T (Fig. 5A, lane 4) and DNAJ2-T (Fig. 5A, lane 8). The amount of hsc70 found associated with chimeric TAgs with a mutation in the conserved histidine residues, HSJ1-T HQ (Fig. 5A, lane 5) and DNAJ2-T HQ (Fig. 5A, lane 9) was reduced significantly, demonstrating that a chimeric $\mathrm{TAg} / \mathrm{hsc} 70$ complex requires an intact J-box sequence. Immunoblot analysis of the same membrane with PAb101 demonstrated that each TAg construct was similarly expressed (Fig. 5A, bottom).

These results were confirmed in mouse embryo fibro- blast (MEF) cells stably expressing the HSJ1-T chimeric TAg. Wild-type TAg and the HSJ1-T chimera produced in these cells interacted with endogenous hsc70, as demonstrated by coimmunoprecipitation of hsc70 with PAb101 (Fig. 5B, lanes 2 and 5, respectively) and vice versa (data not shown). In contrast, neither the J-domain mutants of TAg (H42Q and D44N) (Fig. 5B, lanes 3,4) nor the chimeric TAg mutant (HSJ1-T HQ) (Fig. 5B, lane 6) were found to associate with significant levels of hsc70. TAg mutant $\mathrm{K} 1$ (E107K), which is defective in binding to pRb family members, was competent for hsc70 binding (Fig. 5B, lane 7). Taken together, these data demonstrate that two different J-domains from human DnaJ molecular chaperones (HSJ1 and DNAJ2) can substitute for the amino terminus of $\mathrm{TAg}$ and form a specific complex with hsc70.

\section{The I-domain from two different human DnaI homologs HSI1 and DNAJ2 can substitute for amino-terminal $\mathrm{TAg}$ sequences in promoting efficient SV4O DNA replication in vivo}

The results presented thus far demonstrate that the Jdomain of TAg functions as a DnaJ homolog by mediating a specific interaction with a cochaperone hsc70. To determine whether a heterologous J-domain could substitute for the amino terminus of TAg in mediating SV40 DNA replication, we performed replication assays in vivo similar to those described above for Figure 3. CV-1P cells were cotransfected with vectors expressing the two different chimeric TAgs HSJ1-T and DNAJ2-T, together with an SV40-ori plasmid and assayed for TAg expression and DNA replication. TAg expression from duplicate plates was verified by immunoblot analysis with anti-TAg antibody PAb101 (Fig. 6, bottom). DNA replication was assayed by Southern blot analysis. As shown in Figure 6, top, quantitation of the Southern blot (middle) showed that the HSJ1-T chimera replicated at levels comparable to TAg. The DNAJ2-T chimera functioned less well, but replicated $\sim 10$-fold better than TAg deletion mutant T83-708 (data not shown; Fig. 8A, below), demonstrating that a heterologous J-domain can
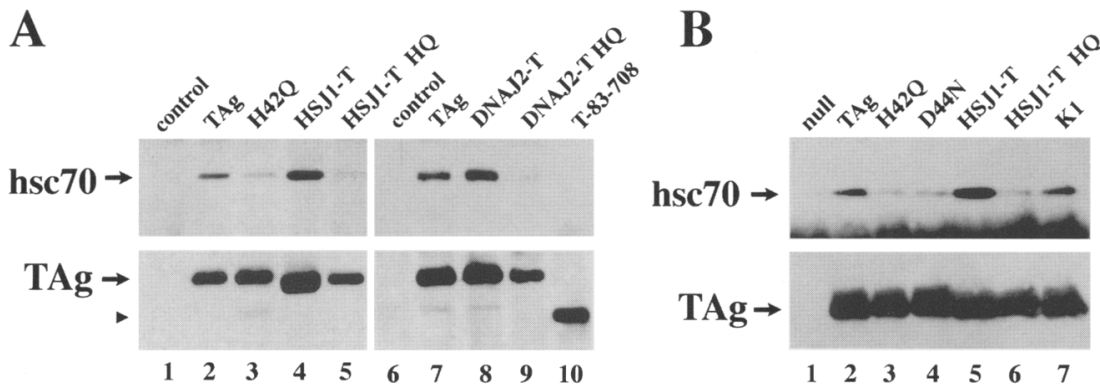

Figure 5. The J-domain from two different human DnaJ homologs can substitute for the amino terminus of TAg in hsc70 binding. $(A)$ Association of human hsc70 with chimeric TAg HSI1-T or DNAJ2-T. U2OS cells were transfected with a vector expressing myc epitope-tagged human hsc70 (myc-hsc70) and the indicated TAg cDNA constructs. At $48 \mathrm{hr}$ post-transfection, cellular extracts were immunoprecipitated with anti-TAg antibody (PAb101) pand immunoblotted with anti-myc antibody (9E10). TAg expression in each lane was detected by probing the identical membrane with PAb101 (bottom). The positions of myc-hsc70 and TAg are indicated by arrows and the position of T83-708 is indicated by an arrowhead. $(B) \mathrm{TAg} / \mathrm{hsc} 70$ complex formation was assayed in MEF cell lines stably expressing the various TAg constructs indicated. Extracts of cells were immunoprecipitated with PAb101 and immunoblotted with anti-hsc70-specific antibody (IB5). TAg expression was confirmed by probing the identical membrane with PAb101 (bottom). The position of hsc70 and TAg are indicated. 
restore DNA replication function to a mutant TAg with an amino-terminal truncation. Mutation of the canonical histidine residue in the J-box of TAg H42Q or the chimeric TAgs HSJ1-T HQ and DNAJ2-T HQ, significantly reduced DNA replication function (Fig. 6, top). These results demonstrate that Dnal chaperone sequences alone are sufficient for the required replication function normally provided by the amino terminus of TAg. These results lend further support to our hypothesis that the amino terminus of TAg mediates specific hsc70 binding and DNA replication in vivo through a bona fide J-domain.

The effect of the TAg I-domain in supporting efficient $D N A$ replication is independent of the I-domain effects on $p R b$ family members

The results shown in Figures 3, 4, and 6 demonstrate that the amino-terminal J-domain is required for effi-

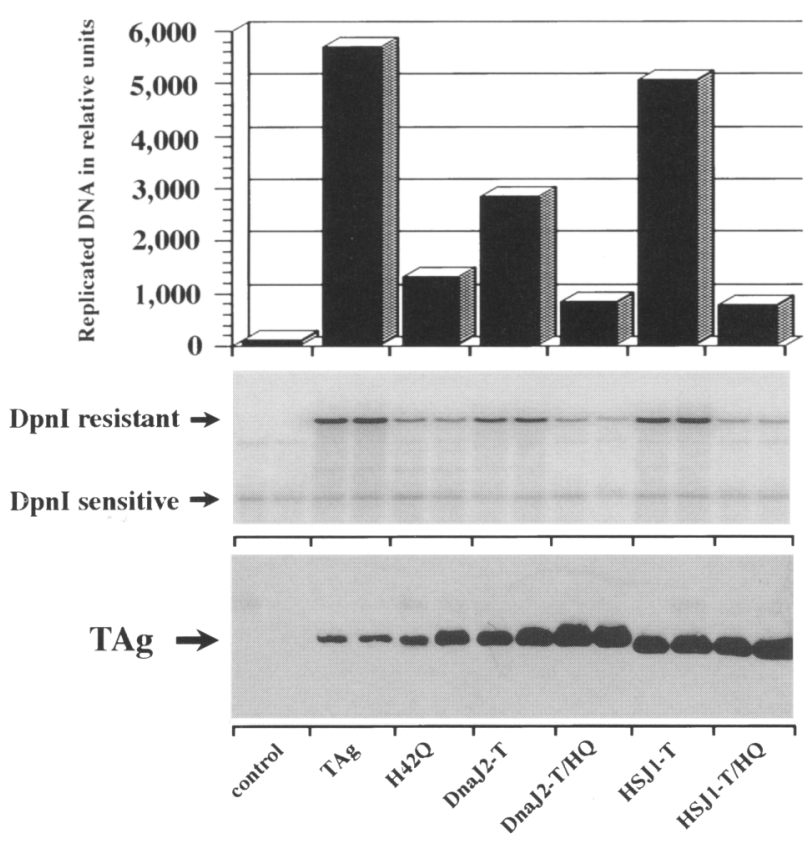

Figure 6. TAg chimeras DNAJ2-T and HSJ1-T function in an SV40 DNA replication assay. CV-1P cells were transfected with the TAg cDNA and chimeric TAg constructs indicated. Cellular extracts were prepared and processed for either DNA replication assay or TAg expression assay as described in Fig. 3. In the representative experiment shown, TAg variants were expressed at approximately equal levels as assayed by immunoprecipitation and immunoblot analysis with anti-TAg antibody PAb101 (bottom). The positions of replicated DNA (DpnI-resistant fragment) and unreplicated DNA (DpnI-sensitive fragment) are indicated (middle). Quantitation of the Southern blot is depicted as a bar graph (top). The bar graph represents replicated DNA in relative (PhosphorImager) units and is based on the average amount of replicated SV40-ori-containing DNA of duplicate samples (middle). Duplicate samples are bracketed and denoted below by name.

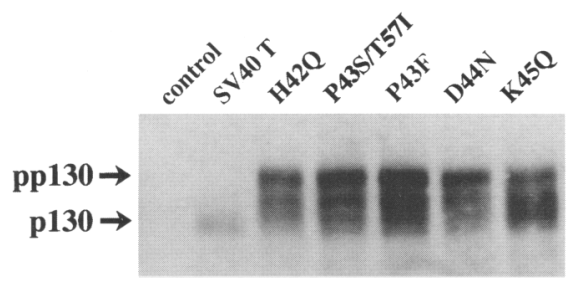

Figure 7. J-domain mutants are defective in altering the phosphorylation state of p130. Extracts of BSC40 cells expressing the genomic constructs indicated were immunoprecipitated with anti-TAg antibody, PAb 101, and immunoblotted with antipl30 antibody C-20. The positions of ppl30 and p130 are indicated.

cient SV40 DNA replication. As previously reported, amino-terminal sequences of TAg may be important for promoting cell cycle progression (Dickmanns et al. 1994), possibly through effects on pRb family members. Moreover, it was shown recently that the amino terminus of TAg is required for altering the phosphorylation state of the cell cycle-regulated pRb-related proteins p130 and p107, but not pRb (Stubdal et al. 1996). Taken together, these results may suggest that the J-domain contributes to DNA replication by affecting the function of $\mathrm{pRb}$ family members in promoting cell cycle progression. As a test of this hypothesis we first wanted to determine whether the J-domain mutants analyzed in this study were impaired in altering the phosphorylation state of p130 and p107. By immunoblot analysis, expression of wild-type TAg significantly reduced the level of p130 phosphorylation, whereas mutants H42Q, P43S/ T57I, P43F, D44N, and K45Q were found to be defective (Fig. 7). Similar results were obtained when we analyzed the phosphorylation state of p107 (data not shown). Furthermore, we noticed that relative to the mutants, wildtype TAg appeared to reduce the overall levels of p130 (Fig. 7).

Given these results, we wanted to determine whether the effects on p130 and p107 are linked with the DNA replication defect we observed (see Figs. 3 and 4). To address this question, we examined the viral DNA replication function of TAg mutant K1 (E107 K). The K1 mutant, which contains an alteration in the LXCXE motif of $\mathrm{TAg}$, is defective for binding to $\mathrm{pRb}$ and $\mathrm{pRb}$ family members p130 and p107 (DeCaprio et al. 1988; Ewen et al. 1989; Zalvide and DeCaprio 1995). As mentioned previously, mutant K1 demonstrated hsc 70 binding (see Fig. $5 B)$. Results of replication assays indicated that $\mathrm{Kl}$ replicates an SV40-ori-containing plasmid at 55-80\% of wild-type TAg (Fig. 8; data not shown), demonstrating that $\mathrm{pRb}$ family members do not appear to play a major role in TAg-mediated DNA replication. These results are consistent with earlier findings that examined the DNA replication function of TAg mutant $\mathrm{Kl}$ (Kalderon and Smith 1984). When compared to wild-type TAg, a mutation within the J-box of TAg (H42Q) or deletion of the entire J-domain (T83-708) reduced significantly DNA replication of an SV40-ori contained plasmid (Fig. 8A). We then examined whether the J-domain effects on 
A

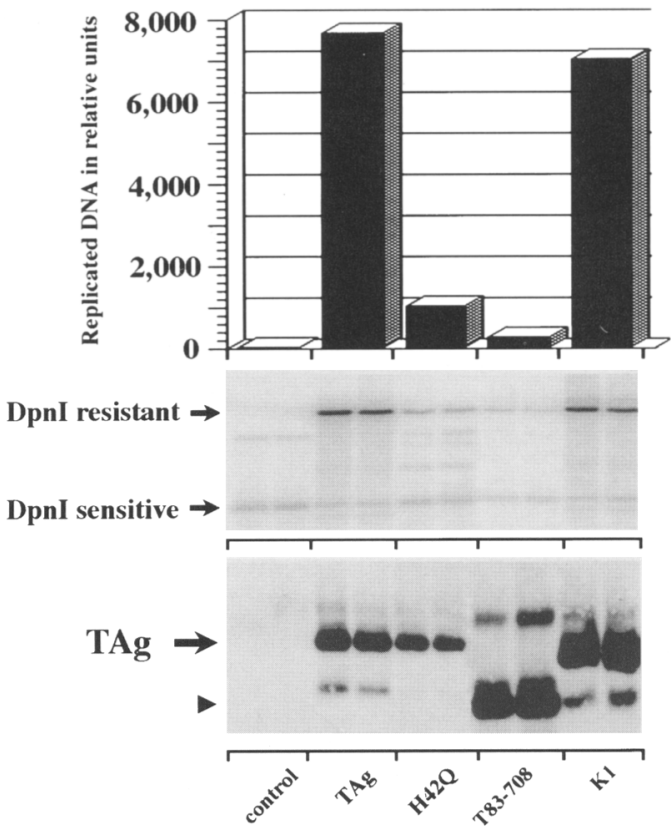

B

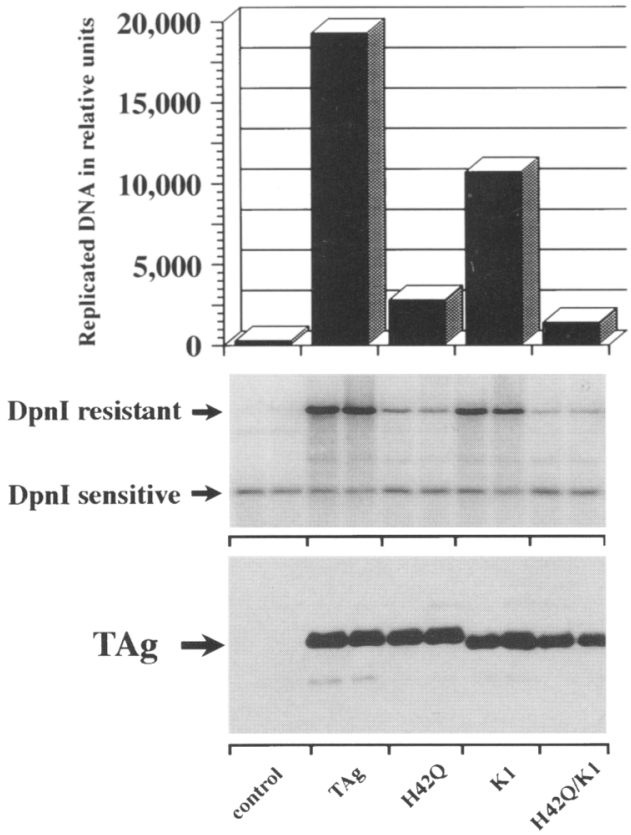

Figure 8. The J-domain effect on DNA replication is unrelated to effects on pRb-related proteins. $\{A, B\rangle \mathrm{CV}-1 \mathrm{P}$ cells were transfected with the TAg cDNA constructs indicated and an SV40-ori-containing plasmid, pSV01 $\triangle E P$. Cell extracts were prepared and processed for either DNA replication assay or TAg expression assay as described in Fig. 3 . In the representative experiments shown, the positions of replicated DNA (DpnI-resistant fragment) and unreplicated DNA (DpnI-sensitive fragment) are indicated (middle). The bar graphs, which represent replicated DNA in relative (PhosphorImager) units, are based on the average amount of replicated SV40-ori-containing DNA of duplicate samples shown in the Southern blots (middles). Expression of TAg variants was detected by immunoprecipitation and immunoblot analysis with anti-TAg antibody PAb101 (bottom). The position of TAg is indicated by an arrow and in $A$ the position of T83-708 (a deletion of the entire TAg J-domain) is indicated by an arrowhead. Duplicate samples are bracketed and denoted below by name.

DNA replication required association with $\mathrm{pRb}$ family members. To address this issue, we constructed a double mutant $(\mathrm{H} 42 \mathrm{Q} / \mathrm{K} 1)$ that is defective in both binding to hsc70 and pRb family members. As seen in Figure 8B, mutant $\mathrm{H} 42 \mathrm{Q} / \mathrm{K} 1$ was as defective in promoting DNA replication as mutant $\mathrm{H} 42 \mathrm{Q}$. Subsequent experiments showed reproducibly the level of replication activity of $\mathrm{H} 42 \mathrm{Q}$ and $\mathrm{H} 42 \mathrm{Q} / \mathrm{K} 1$ to be similar (data not shown), demonstrating that $\mathrm{pRb}$ family members do not appear to be involved in the J-domain-mediated defect in DNA replication under the experimental conditions used here. We cannot, however, rule out the possibility that the J-domain effects on $\mathrm{pRb}$ family members $\mathrm{p} 130$ and $\mathrm{p} 107$ may play a role in SV40 DNA replication under certain circumstances. This possibility appears to be unlikely, because in both plasmid and viral DNA replication assays TAg mutant K1 replicates DNA at or near wild-type levels (Kalderon and Smith 1984) (Fig. 8). Taken together, these data indicate that the primary effect on viral DNA replication contributed by the J-domain appears to be independent of $\mathrm{pRb}$ family members.

\section{Discussion}

Extensive genetic and biochemical studies have demonstrated that TAg amino-terminal residues are important for several TAg-mediated functions. However, the nature of the biochemical activity required to carry out these functions has been largely undefined. By sequence comparison, the amino-terminal residues of polyomavirus TAgs were shown to share sequence homology with the J-domain of DnaJ/hsp40 family of molecular chaperones. We have provided evidence that the amino terminus of TAg represents a bona fide J-domain that shares not only sequence homology, but also functional homology to DnaJ/hsp40 molecular chaperones. Furthermore, we demonstrated that the TAg J-domain is required for efficient DNA replication and the specific association of the constitutively expressed hsc70 protein. In related reports, we show that viral TAgs also use their J-domains to achieve a distinct effect on control of cell cycle progression by altering the phosphorylation state of $\mathrm{pRb}$ related proteins p130 and p107 (H. Stubdal, I. Zalvide, K.S. Campbell, C. Schweitzer, T.M. Roberts, and J.A. DeCaprio, in prep.; Q. Sheng, D. Denis, M. Ratnofsky, T.M. Roberts, J.A. DeCaprio, and B.S. Schaffhausen, in prep.) and the overall levels of p130 through a proteasome dependent degradation pathway (H. Stubdal, J. Zalvide, K.S. Campbell, C. Schweitzer, T.M. Roberts, and J.A. DeCaprio, in prep.). Our findings provide evidence that the $\mathrm{J}$ domain-dependent effects on p130 and p107 do not appear to be linked to the replication defects we observed 
(Fig. 8), suggesting at least a dual role for the J-domain in TAg-mediated functions.

DnaJ proteins function as cofactors by associating directly with and modifying the ATPase activity of a member of the hsp70 chaperone family (Silver and Way 1993; Hartl 1996). Together, these proteins function in a complex to catalyze essential cellular processes including protein synthesis, translocation, and proteolysis /Gething and Sambrook 1992; Georgopoulos and Welch 1993; Hartl 1996). These reactions involve the ability of hsp70 to recognize short (7- to 9-mer) sequences (Flynn et al. 1991) that are thought to be exposed on the hydrophobic surfaces of misfolded, denatured, or mutant proteins (Pelham 1986). In this study, we demonstrate that hsc70 forms a specific complex with TAg, and this interaction is dependent on the J-domain of TAg. The genetic analyses in this report, using amino acid substitution mutants and chimeric TAgs, demonstrated that the $\mathrm{TAg} / \mathrm{hsc} 70$ complex is distinct from an interaction between hsp70 family members and nonnative substrates, and appears to be analogous to the interaction between an hsp70 family member and its respective cofactor DnaJ. Indeed, our data are supported by biochemical and genetic studies that have demonstrated that mutations within and surrounding the J-box of DnaJ homologs from E. coli and yeast block DnaJ chaperone function (Feldheim et al. 1992; Wild et al. 1992; Brodsky and Schekman 1993; Scidmore et al. 1993; Wall et al. 1994, 1995; Schlenstedt et al. 1995; Dey et al. 1996; Tsai and Douglas 1996).

Through DNA replication analyses, we have found that the novel TAg J-domain plays a critical role in efficient viral DNA replication in vivo. Our findings are in agreement with previous studies that demonstrated that amino-terminal sequences of TAg are necessary for DNA replication (Gluzman and Ahrens 1982; Pipas et al. 1983; Srinivasan et al. 1989; Marsilio et al. 1991; Maulbecker et al. 1992; Peden and Pipas 1992; Weisshart et al. 1996). The data presented herein extend these findings by demonstrating that an intact HPDK motif that is conserved among all polyomavirus tumor antigens, and is invariant in nearly all DnaJ homologs, is required for efficient DNA replication. As a further genetic analysis, we analyzed the ability of chimeric TAgs to replicate an SV40ori-containing plasmid. We demonstrated that chimeric TAgs containing the J-domain of two different human DnaJ homologs restored DNA replication function to TAg J-domain mutants, providing strong evidence that TAg requires a Dnal protein sequence to manipulate a component of the molecular chaperone machinery to mediate efficient DNA replication (Fig. 6). Notably, our findings provide an initial demonstration of a eukaryotic virus that has incorporated molecular chaperone sequences into its genome to carry out a function essential to its life cycle. Furthermore, the data presented herein provide the first evidence of a regulatory function for molecular chaperones in the process of DNA replication in a eukaryotic cell.

As discussed earlier, our data imply a parallel between the replication of SV40 and bacteriophage $\lambda$. A DnaJ/ DnaK(hsp70) complex is known to play a critical role in the replication of bacteriophage $\lambda$ in $E$. coli (Wall et al. $1994,1995)$. In the process of bacteriophage $\lambda$ replication, viral proteins $\lambda \mathrm{O}$ and $\lambda \mathrm{P}$ are required to recruit cellular chaperones DnaJ and DnaK to a multiprotein replication complex assembled at the $\lambda$-ori (Alfano and McMacken 1989; Zylicz et al. 1989). Subsequent to binding, DnaJ and DnaK function together to initiate a series of temporal events that result in the initiation of $\lambda$ replication (Alfano and McMacken 1989; Zylicz et al. 1989). Similar to replication of bacteriophage $\lambda, \mathrm{TAg}$ forms a multiprotein complex at the origin (Challberg and Kelly 1989; Stillman 1989; Borowiec et al. 1990). However, $\lambda$ replication requires two viral proteins in addition to the host proteins DnaJ, DnaK, GrpE (a nucleotide exchanger), and DnaB helicase. It is possible that TAg has evolved a similar, albeit more efficient, strategy of promoting viral DNA replication through an intrinsic J-domain to interact directly with a cochaperone. Our data suggest a striking example of evolutionary conservation as two viruses as distant as bacteriophage $\lambda$ and SV40 each make use of a molecular chaperone complex to promote viral DNA replication, and delineates a conserved mechanism for viral DNA replication and perhaps for eukaryotic cellular DNA replication.

Although several models can be invoked to explain a chaperone-dependent effect on viral DNA replication, one model takes into account the similarities between replication of SV40 and bacteriophage $\lambda$. In this scenario, it could be envisioned that the J-domain is involved in catalyzing intra- or intermolecular rearrangements of the oligomeric complex assembled at the origin. This may involve the ability of hsc70 to regulate conformationally TAg or TAg-associated replication proteins to activate the replication complex. Alternatively, because chaperones are known to regulate macromolecular assembly/ disassembly events, a TAg J-domain associated activity may be necessary for assembling TAg hexamers that are known to be positioned around the ori-DNA in the process of SV40 DNA replication (Borowiec et al. 1990; Dean et al. 1992; Wessel et al. 1992). Because molecular chaperones have been shown to play a role in a wide variety of processes, it will be important to determine what aspect in the regulatory function of hsc70 is involved in promoting efficient SV40 DNA replication.

A number of other TAg-mediated functions require amino-terminal sequences. Whether these functions are also J-domain dependent is presently unknown. The results presented here point to the possibility of a chaperone involvement in these diverse amino-terminal-mediated processes that include transcriptional regulation, virion assembly, stability, and oligomerization. Notably, there is evidence to suggest that molecular chaperones play a regulatory role in these normal cellular processes (Rutherford and Zucker 1994; Hartl 1996). It is of interest to determine whether these other TAg-mediated functions that appear to reside at the amino terminus are a function of the J-domain and whether these functions impact on the process of DNA replication. It appears that the transformation and cell cycle progression functions, which require amino-terminal sequences, can be attrib- 
uted to J-domain-dependent effects on pRb-related proteins p130 and p107 (H. Stubdal, J. Zalvide, K.S. Campbell, C. Schweitzer, T.M. Roberts, and J.A. DeCaprio, in prep.).

In conclusion, SV40 has provided the major model system for the study of eukaryotic DNA replication. Extensive biochemical analysis of the requirements for SV40 DNA replication in vitro has led to the identification of many of the components necessary for eukaryotic DNA replication (Waga and Stillman 1994). The data presented here provide a novel direction in the study of eukaryotic DNA synthesis by demonstrating the importance of the chaperone system for efficient SV40 DNA replication. A requirement for a specific J-domain activity has not been noted in cell free DNA replication systems (Challberg and Kelly 1989; Stillman 1989). However, some elements important to the regulation of DNA synthesis have been demonstrated to be important in in vitro systems, although initially they were not considered to be part of the basal replication complex. The activation of DNA replication by a cyclin/cdc complex and protein phosphatase 2A are two examples (McVey et al. 1989; D'Urso et al. 1990; Virshup et al. 1989, 1992). Further studies that account for a role of chaperones in in vitro replication systems should contribute to our understanding of DNA replication. It will be of considerable interest to see where this new direction connecting molecular chaperones to DNA replication leads.

\section{Materials and methods}

\section{Plasmids}

Plasmid pRSV-BneoT (J.M. Pipas, unpubl.) was constructed by cloning a fragment from a full-length TAg genomic DNA that extends from the StuI site (5190) to the BamHI (2533) into the SmaI and BamHI sites of PGEM3Z+ (Promega)-based vector that contains the neomycin gene under the control of the RSV promoter. PCR-directed mutagenesis with Taq DNA polymerase was used to introduce mutations $\mathrm{H} 42 \mathrm{Q}, \mathrm{K} 45 \mathrm{Q}$, and G47E into the TAg genomic DNA of vector pRSV-BneoT. For H42Q, the upstream primer $\mathrm{T} 7$ (Promega), downstream primer 5'CTCCTCCTTTATCAGGCTGAAACTCC-3', and template pRSV-BneoT were used for PCR. The PCR product was digested with $S a c I$ and EcoNI and subcloned into pRSV-BneoT. The $\mathrm{K} 45 \mathrm{Q}$ and G47E mutations were created using the same downstream primer-5'-AAGTTCAGCCTGTCCAAGGGC-3' with $5^{\prime}$-TCATCCTGATCAAGGAGGAG- $3^{\prime}$ as the upstream primer for K45Q and 5'-TCATCCTGATAAAGGAGAGATGAAG-3' as the upstream primer for G47E. EcoNI-digested PCR products were subcloned into pRSV-BneoT. Vectors containing the mutations P43S/T57I, P43F, and D44N (Peden and Pipas 1992) were used to create the corresponding $\mathrm{pRSV}-\mathrm{BneoT}$-based vectors.

pCMV-TAg was cloned by ligating the BamHI insert containing the cDNA for SV40 large T antigen from pSG5-T (Zalvide and DeCaprio 1995) into pCMV digested with BamHI (Pasleau et al. 1985). Similarly, pCMV-K1 was cloned by inserting the BamHI digest from pSG5-K1 (Zalvide and DeCaprio 1995). A PfIMI-PstI fragment from pZIP-T83-708 (Montano et al. 1990) was cloned into pSG5-T to yield pSG5-T83-708. The BamHI fragment was cloned into pCMV to yield pCMV-T83-708. To generate pCMV-H42Q, D44N, H42Q/K1，HSJ1，HSJ1-HQ,
DNAJ2, and DNAJ2 HQ, an EcoRI-PfIMI fragment from the respective pSG5 plasmids (H. Stubdal, J. Zalvide, K.S. Campbell, C. Schweitzer, T.M. Roberts, and J.A. DeCaprio, in prep.) was inserted into pCMV-TAg cut with same enzymes.

pCMV-myc/hsc70 contains an amino-terminal triple tandem myc epitope-tagged cDNA for human hsc70 cloned into the BamHI site of pCMV (Pasleau et al. 1985). pCMV-myc/hsc70 was created by ligating PCR amplified human hsc 70 cDNA and triple tandem myc epitope tag into pCMV digested with $B a m H I$. The upstream primer 5'-GTCTCTAGAATGTCCAAGGGACCTGCAG-3' and 5'-GGCGTCGACAGATCTTTAATCAACCTCTTCAATGG-3' as the downstream primer were used to amplify hsc 70 from pACTHHSC70-4.2 provided by John Lednicky (Baylor College of Medicine, Houston, TX). The upstream 5'-GTCGGATCCGCCACCATGGAACAAAAGTTGATTTCTG3' and 5'-GTCTCTAGAGTTCAAGTCTTCTTCTGAG-3' as the downstream primer were used to amplify triple tandem myc epitope from pB296.myc (Pellman et al. 1995) provided by David Pellman (Dana Farber Cancer Institute). The triple tandem myc epitope tag contains three copies of the peptide sequence GluGlnLysIleSerGluGluAspLeuAsn with a Gly residue between each sequence.

SV40-ori-containing plasmid pSV01 $\triangle E P$ used for DNA replication assays (Wobbe et al. 1985) was a kind gift of Peter Bullock (Tufts University School of Medicine).

\section{Cell culture and transfection}

BSC 40, CV-1P, monkey kidney cells, and BALB/c 3T3 clone A31 cells were maintained in Dulbecco's modified Eagle medium (DMEM) supplemented with $8 \%$ bovine calf serum (GIBCO). Human U20S (ATCC) and MEF cells stably expressing TAg, H42Q, D44N, HSJ1-T, HSJ1-T HQ, and K1 TAg (H. Stubdal, J. Zalvide, K.S. Campbell, C. Schweitzer, T.M. Roberts, and J.A. DeCaprio, in prep.) were grown in DMEM supplemented with $10 \%$ fetal calf serum (JRH Sciences). Hybridoma cell lines PAb101 (ATCC) and 9E10 (ATCC) were maintained in DMEM supplemented with $10 \%$ fetal calf serum.

For transient transfections, $100 \mathrm{~mm}$ plates of $\sim 50 \%$ confluent cells were transfected by the calcium phosphate procedure (Cherington et al. 1986). The DNA-calcium phosphate precipitate was added to the culture medium and left on cells for $4 \mathrm{hr}$. After removal of the precipitate, a 7-min glycerol shock was performed and the cells were washed once with serum-free DMEM, refed with complete medium and lysed 40-48 hr later.

\section{Stable cell lines}

The wild-type pRSV-BneoT and mutant constructs [pRSVBneoT(H42Q), pRSV-BneoT(P43S/T57I), pRSV-BneoT(P43F), pRSV-BneoT(D44N), pRSV-BneoT(K45Q), and pRSV-BneoT[G47E)] as well as pGem RSVneo, the backbone plasmid that is the precursor of pGemT-RSVneo, were transfected into BSC40 cells and BALB/c 3T3 clone A31 cells $1-50 \%$ confluencey on $100 \mathrm{~mm}$ plates) by standard calcium phosphate precipitation as described above. At $48 \mathrm{hr}$ post-transfection, cells were trypsinized and replated at a 1:4 dilution in complete medium containing $0.4 \mathrm{mg} / \mathrm{ml}$ of G418 (neomycin sulfate). After 3 weeks in selection medium, -500 neomycin-resistant colonies were pooled and assayed for the synthesis of the relevant wild-type and mutant TAg species by immunoblotting.

\section{Antibodies}

PAb101, a monoclonal antibody that reacts with a carboxy-terminal epitope of TAg (ATCC), PAb419, a monoclonal antibody 
that reacts with SV40 TAg and small $\mathrm{t}$ (Harlow et al. 1981), and 9E10, a monoclonal antibody that reacts with myc (ATCC) were obtained by pooling tissue culture supernatants from growing hybridoma cell cultures. Monoclonal antibody N27 that reacts with hsc70 and hsp70, polyclonal antibody anti-hsp 73, that reacts specifically with hsc 70 , and monoclonal antibody C92 that reacts specifically with hsp70 were graciously provided by William J. Welch (University of California, San Fransisco). Monoclonal antibody IB5 that reacts specifically with hsc70 was obtained from Stressgen. Polyclonal antibody C-20 that reacts with pRb-related protein p130 was obtained from Santa Cruz. The null monoclonal antibody was described previously (Ewen et al. 1989).

\section{Immunoprecipitation, gel electrophoresis, and Western blotting}

Dishes $(150 \mathrm{~mm})$ of cells were grown to confluence, washed twice with ice-cold PBS, and lysed $15 \mathrm{~min}$ in $1.0 \mathrm{ml}$ of Nonidet P-40 (NP-40) lysis buffer [1\% NP-40, 10\% glycerol, $137 \mathrm{~mm}$ $\mathrm{NaCl}, 5 \mathrm{~mm}$ EDTA, $20 \mathrm{~mm}$ Tris $(\mathrm{pH} 8.0)]$ containing $5 \mathrm{~mm}$ sodium fluoride, $1 \mathrm{~mm}$ sodium orthovanadate, $25 \mathrm{~mm} \beta$-glycerophosphate, and $10 \mu \mathrm{g}$ of each of the following protease inhibitors: aprotinin, pepstatin, and leupeptin. Cell lysates were scraped from the dishes, and cleared at $13,000 \mathrm{~g}$ and protein concentration was determined by Bradford assay (Bio-Rad). Cell lysates were incubated with the relevant antibodies: $50 \mu \mathrm{l}$ of tissue culture supernatant in the case of anti-TAg antibody PAb101, and $2 \mu \mathrm{g}$ of anti-hsc70 antibody IB5 (Stressgen), for at least $1 \mathrm{hr}$ with rocking at $4^{\circ} \mathrm{C}$ and then for 30 min with $30 \mu \mathrm{l}$ of newly resuspended and washed protein A-Sepharose beads (Pharmacia), mixed 1:1 with distilled $\mathrm{H}_{2} \mathrm{O}$ for PAb101, and $20 \mu \mathrm{l}$ of protein G Plus-agarose (Santa Cruz Biotechnology) for IB5. The immune complexes were washed four times with NP-40 lysis buffer, two times with $0.5 \mathrm{M} \mathrm{LiCl} / 20 \mathrm{~mm}$ Tris $(\mathrm{pH} 8.0\rangle$, and a final wash with NP-40 lysis buffer, boiled in sample buffer, and analyzed by SDS-polyacrylamide gel electrophoresis in $7.5 \%$ polyacrylamide gels (Laemmli 1970). Proteins were transferred to Bioblot-nitrocellulose membranes (Costar) and immunoblotting was performed by standard procedures (Towbin et al. 1979). The membranes were blocked for $30 \mathrm{~min}$ with $5 \%$ nonfat dry milk in PBS, before incubation with either a 1:3000 dilution of anti-hsc 70/hsp70 antibody N27, 1:2000 dilution of antihsc70 antibody anti-hsp73, 1:5000 dilution of anti-hsp70 antibody C92, 1:20,000 dilution of anti-hsc70 antibody IB5 (Stressgen), 1:50 dilution of anti-TAg antibodies PAb101 or PAb419, 1:50 dilution for anti-myc antibody 9E10, or 1:2000 dilution of anti-p130 antibody C-20 (Santa Cruz). Detection of immune complexes was performed with the appropriate horseradish peroxidase-conjugated secondary antibody (Jackson ImmunoResearch). Washed immunoblots were developed using enhanced chemiluminescence (ECL) (Amersham) according to the manufacturer's protocol.

\section{Viral replication assay}

Replication assays were performed according to methods described previously (Kalderon and Smith 1984; Gjørup et al. 1994). CV-1P cells were cotransfected with TAg expression plasmids and an SV40-ori-containing plasmid pSV01 $\triangle E P$ (Wobbe et al. 1985 / by the calcium phosphate method essentially as described above. Cells were plated at a density of $3 \times 10^{5}$ on $60 \mathrm{~mm}$ plates the day before transfection. For each $60-\mathrm{mm}$ plate, $1.5 \mu \mathrm{g}$ of pSV01 $\Delta \mathrm{EP}$ plasmid was transfected together with $2.0 \mu \mathrm{g}$ of TAg expression plasmids. To assay for TAg expression, duplicate plates were transfected in parallel. The cells were harvested
$48 \mathrm{hr}$ after transfection and assayed for protein expression by immunoprecipitation of TAg and subsequent immunoblotting or replication efficiency by Southern analysis. The isolated low molecular weight DNA was digested with $D p n I$ to distinguish replicated DNA from input and also with HincII to linearize pSV01 $1 \mathrm{EP}$. For Southern blot analysis, one-tenth of the low molecular weight DNA from each $60-\mathrm{mm}$ plate was used for replication assays. The ${ }^{32} \mathrm{P}$-labeled probe was a random hexamer-primed 314-bp EcoRI restriction fragment from pSV01 $\triangle E P$ containing the SV40 origin. Bands were visualized and quantitated using a Molecular Dynamics PhosphorImager.

\section{Acknowledgments}

We thank David Livingston for critical comments and suggestions; William Welch for generously providing the heat shock protein antibodies and for helpful disscussions; Franz-Ulrich Hartl for reviewing the manuscript; John Lednicky for providing the human hsc70 clone and communicating unpublished data; Bill Kaelin for CV-1P cells; Zolt Arany for PAb419; Charles Sherr for BALB/c 3T3 cells; Akio Yamakawa for 9E10; David Pellman for providing the triple tandem myc eptitope tag plasmid pB296; Ellen Fanning for advice, DNA polymerase $\alpha$ antibody and communicating unpublished data; Lorraine Laham and Radha Narsimhan for valuable suggestions and encouragement; Chuck Stiles for stimulating discussions, support and critical comments on the manuscript. Supported by grants from the National Institutes of Health (NIH) to T.M.R., P.A.S., B.S.S., and J.A.D.

The publication costs of this article were defrayed in part by payment of page charges. This article must therefore be hereby marked "advertisement" in accordance with 18 USC section 1734 solely to indicate this fact.

\section{References}

Alfano, C. and R. McMacken. 1989. Heat shock protein-mediated disassembly of nucleoprotein structures is required for the initiation of bacteriophage lambda DNA replication. $/$. Biol. Chem. 264: 10709-10718.

Arthur, A., A. Höss, and E. Fanning. 1988. Expression of simian virus $40 \mathrm{~T}$ antigen in Escherichia coli: Localization of $\mathrm{T}$ antigen origin DNA-binding domain to within 129 amino acids. J. Virol. 62: 1999-2006.

Borowiec, J.A., F.B. Dean, P.A. Bullock, and J. Hurwitz. 1990. Binding and unwinding-How $\mathrm{T}$ antigen engages the SV40 origin of DNA replication. Cell 60: 181-184.

Bradley, M. 1990. Activation of ATPase activity of simian virus 40 large $T$ antigen by the covalent affinity analog of ATP, fluorosulfonylbenzoyl 5'-adenosine. J. Virol. 64: 4939-4947.

Brodsky, J.L. and R. Schekman. 1993. A Sec63p-BiP complex from yeast is required for protein translocation in a reconstituted proteoliposome. J. Cell Biol. 123: 1355-1363.

Challberg, M.D. and T.J. Kelly. 1989. Animal virus DNA replication. Annu. Rev. Biochem. 58: 671-717.

Cheetham, M.E., J.-P. Brion, and B.H. Anderton. 1992. Human homologs of the bacterial heat-shock protein Dna) are preferentially expressed in neurons. Biochem. J. 284: 469-476.

Cherington, V., B. Morgan, M. Spiegelman, and T.M. Roberts. 1986. Recombinant retroviruses that transduce individual polyoma tumor antigens: Effects on growth and differentiation. Proc. Natl. Acad. Sci. 83: 4307-4311.

Clark, R., D.P. Lane, and R. Tjian. 1981. Use of monoclonal antibodies as probes of Simian virus $40 \mathrm{~T}$ antigen ATPase activity. I. Biol. Chem. 256: 11854-11858.

Cole, C.M., J. Tornow, R. Clark, and R. Tjian. 1986. Properties 
of the simian virus 40 (SV40) large $\mathrm{T}$ antigens encoded by SV40 mutants with deletions in gene A. I. Virol. 57: 539-546.

Collins, K.L. and T.J. Kelly. 1991. The effects of T antigen and replication protein $\mathrm{A}$ on the initiation of DNA synthesis by DNA polymerase $\alpha$-primase. Mol. Cell. Biol. 11: 2108-2115.

D'Urso, G., R.L. Marraccino, D.R. Marshak, and J.M. Roberts. 1990. Cell cycle control of DNA replication by a homolog from human cells of the $\mathrm{p} 34^{\mathrm{cdc} 2}$ protein kinase. Science 250: 786-791.

Dean, F., J. Borowiec, T. Eki, and J. Hurwitz. 1992. The simian virus $40 \mathrm{~T}$ antigen double hexamer assembles around the DNA at the replication origin. J. Biol. Chem. 267: 1412914137.

DeCaprio, J.A., J.W. Ludlow, J. Figge, J.-Y. Shew, C.-M. Huang, W.-H. Lee, E. Marsilio, E. Paucha, and D.M. Livingston. 1988. SV40 large T antigen forms a specific complex with the product of the retinoblastoma susceptibility gene. Cell 54: $275-283$.

Dey, B., A.J. Caplan, and F. Boschelli. 1996. The Ydil molecular chaperone facilitates formation of active $\mathrm{p} 60^{\mathrm{v}-\mathrm{src}}$ in yeast. Mol. Biol. Cell 7: 91-100.

Dickmanns, A., A. Zeitvogel, F. Simmersbach, R. Weber, A. Arthur, S. Dehde, A. Wildeman, and E. Fanning. 1994. The kinetics of simian virus 40 -induced progression of quiescent cells into S-Phase depend on four independent functions of large $\mathrm{T}$ antigen. $J$. Virol. 68: 5496-5508.

Dornreiter, I., L.F. Erdile, I.U. Gilbert, D. von Winkler, T.J. Kelly, and E. Fanning. 1992. Interaction of DNA polymerase alpha-primase with cellular replication protein A and SV40 T antigen. EMBO I. 11: 769-776.

Ewen, M.E., J.W. Ludlow, E. Marsilio, J.A. Decaprio, R.C. Millikan, S.H. Cheng, E. Paucha, and D.M. Livingston. 1989. An $\mathrm{N}$-terminal transformation-governing sequence of SV40 large $\mathrm{T}$ antigen contributes to the binding of both p110RB and a second cellular protein, p120. Cell 58: 257-267.

Feldheim, D., J. Rothblatt, and R. Schekman. 1992. Topology and functional domains of Sec63p, an endoplasmic reticulum membrane protein required for secretory protein translocation. Mol. Cell. Biol. 12: 3288-3296.

Flynn, G.C., J. Pohl, M.T. Flocco, and J.E. Rothman. 1991. Peptide binding specificity of the molecular chaperone BiP. $\mathrm{Na}$ ture 353: 726-730.

Georgopoulos, C. and W.J. Welch. 1993. Role of the major heat shock proteins as molecular chaperones. Annu. Rev. Cell Biol. 9: 601-634.

Gething, M.-J. and J. Sambrook. 1992. Protein folding in the cell. Nature 355: 33-44.

Gish, W.R. and M.R. Botchan. 1987. Simian virus 40 transformed human cells that express large $\mathrm{T}$ antigens defective for viral DNA replication. J. Virol. 61: 2864-2876.

Gjørup, O., P. Rose, P. Holman, B. Bockus, and B. Schaffhausen. 1994. Protein domains connect cell cycle stimulation directly to initiation of DNA replication. Proc. Natl. Acad. Sci. 91: 12125-12129.

Gluzman, Y. and B. Ahrens. 1982. SV40 early mutants that are defective for viral DNA synthesis but competent for transformation of cultured rat and simian cells. Virology 123: 7892.

Gruda, M.C., J.M. Zabolotny, J.H. Xiao, I. Davidson, and J.C. Alwine. 1993. Transcriptional activation by simian virus 40 large $\mathrm{T}$ antigen: Interactions with multiple components of the transcription complex. Mol. Cell. Biol. 13: 961-969.

Harlow, E., L.V. Crawford, D.C. Pim, and N.M. Williamson. 1981. Monoclonal antibodies specific for simian virus $40 \mathrm{tu}-$ mor antigens. J. Virol. 39: 861-869.

Hartl, F.W. 1996. Molecular chaperones in cellular protein fold- ing. Nature 381: 571-580

Hill, R.B., J.M. Flanagan, and J.H. Prestegard. 1995. 1H and 15N magnetic resonance assignments, secondary structure, and tertiary fold of Escherichia coli DnaJ (1-78). Biochemistry 34: 5587-5589.

Kalderon, D. and A.E. Smith. 1984. In vitro mutagenesis of a putative DNA binding domain of SV40 large-T. Virology 139: 109-137.

Kelley, W.L. and S.J. Landry. 1994. Chaperone power in a virus? Trends Biochem. Sci. 19: 277-278.

Kierstead, T.D. and M.J. Tevethia. 1993. Association of p53 binding and immortalization of primary $\mathrm{C} 57 \mathrm{BL} / 6$ mouse embryo fibroblasts by using simian virus $40 \mathrm{~T}$-antigen $\mathrm{mu}-$ tants bearing internal overlapping deletion mutations. J. Virol. 67: 1817-1829.

Laemmli, U.K. 1970. Cleavage of structural proteins during the assembly of the head of bacteriophage T4. Nature 227: 680685.

Manos, M. and Y. Gluzman. 1985. Genetic and biochemical analysis of transformation-competent, replication-defective simian virus 40 large $\mathrm{T}$ antigen mutants. I. Virol. 53: 120127.

Marsilio, E., S.H. Cheng, B. Schaffhausen, E. Paucha, and D.M. Livingston. 1991. The $\mathrm{T} / \mathrm{t}$ common region of simian virus 40 large $\mathrm{T}$ antigen contains a distinct transformation-governing sequence. J. Virol. 65: 5647-5652.

Maulbecker, C., I. Mohr, Y. Gluzman, J. Bartholomew, and M. Botchan. 1992. A deletion in the simian virus 40 large $T$ antigen impairs lytic replication in monkey cells in vivo but enhances DNA replication in vitro: New complementation function of T antigen. J. Virol. 66: 2195-2207.

McVey, D., L. Brizuela, I. Mohr, D. Marshak, Y. Gluzman, and D. Beach. 1989. Phosphorylation of large tumor antigen by cdc2 stimulates SV40 DNA replication. Nature 341: 503507.

Melendy, T. and B. Stillman. 1993. An interaction between replication protein A and SV40 T antigen appears essential for primosome assembly during SV40 DNA replication. I. Biol. Chem. 268: 3389-3395.

Montano, X., R. Millikan, J.M. Milhaven, D.A. Newsome, J.W. Ludlow, A.K. Arthur, E. Fanning, I. Bikel, and D.M. Livingston. 1990. Simian virus 40 small tumor antigen and an amino-terminal domain of large tumor antigen share a common transforming function. Proc. Natl. Acad. Sci. 87: 74487452.

Oh, S., A. Iwahori, and S. Kato. 1993. Human cDNA encoding DnaJ protein homolog. Biochem. Biophys. Acta. 1174: 114116.

Pasleau, F., M.J. Tocci, F. Leung, and J.J. Kopchick. 1985. Growth hormone gene expression in eukaryotic cells directed by the Rous sarcoma virus long terminal repeat or cytomegalovirus immediate-early promoter. Gene 38: $227-$ 232.

Paucha, E., D. Kalderon, R.W. Harvey, and A.E. Smith. 1986. Simian virus 40 origin DNA-binding domain on large $T$ antigen. J. Virol. 57: 50-64.

Peden, K.W. and J.M. Pipas. 1992. Simian virus 40 mutants with amino-acid substitutions near the amino terminus of large $T$ antigen. Virus Genes 6: 107-118.

Peden, K.W.C., S.L. Spence, L.C. Tack, C.A. Cartwright, A. Srinivasan, and J.M. Pipas. 1990. A DNA replication-positive mutant of simian virus 40 that is defective in transformation and the production of infectious virions. J. Virol. 64: 29122921.

Pelham, H.R.B. 1986. Speculations on the functions of the major heat shock and glucose regulated proteins. Cell 46: 959-961. 
Pellecchia, M., T. Szyperski, D. Wall, C. Georgopoulos, and K. Wuthrich. 1996. NMR structure of the J-domain and the Gly/Phe-rich region of the Escherichia coli DnaJ chaperone. J. Mol. Biol. 260: 236-250.

Pellman, D., M. Bagget, H. Tu, and G.R. Fink. 1995. Two microtubule-associated proteins required for anaphase spindle movement in Saccharomyces cerevisiae. J. Cell Biol. 130: $1373-1385$.

Pipas, J., K. Peden, and D. Nathans. 1983. Mutational analysis of simian virus $40 \mathrm{~T}$ antigen: Isolation and characterization of mutants with deletions in the T-antigen gene. Mol. Cell. Biol. 3: 203-213.

Qian, Y.Q., D. Patel, F.U. Hartl, and D.J. McColl. 1996. Nuclear magnetic resonance solution structure of the human Hsp40 (HDJ-1) J-domain. J. Mol. Biol. 260: 224-235.

Quartin, R.S., C.N. Cole, J.M. Pipas, and A.J. Levine. 1994. The amino-terminal functions of the simian virus 40 large $T$ antigen are required to overcome wild-type p53-mediated growth arrest of cells. J. Virol. 58: 526-535.

Rutherford, S.L. and C.S. Zucker. 1994. Protein folding and the regulation of signaling pathways. Cell 79: 1129-1132.

Sawai, E.T. and J.S. Butel. 1989. Association of a cellular heat shock protein with simian virus 40 large $\mathrm{T}$ antigen in transformed cells. J. Virol. 63: 3961-3973.

Schlenstedt, G., S. Harris, B. Risse, R. Lill, and P.A. Silver. 1995. A yeast DnaJ homolog, Scjlp, can function in the endoplasmic reticulum with $\mathrm{Bip} / \mathrm{Kar} 2 \mathrm{p}$ via a conserved domain that specifies interactions with hsp70s. I. Cell Biol. 129: 979-988.

Schmieg, F. and D. Simmons. 1988. Characteriztion of the in vitro interaction between SV40 $\mathrm{T}$ antigen and p53: Mapping the p53 binding site. Virology 164: 132-140.

Scidmore, M.A., H.H. Okamura, and M.D. Rose. 1993. Genetic interactions between KAR2 and SEC63, encoding eukaryotic homologs of DnaK and DnaJ in the endoplasmic reticulum. Mol. Biol. Cell 4: 1145-1159.

Silver, P.A. and J.C. Way. 1993. Eukaryotic DnaJ homologs and the specificity of Hsp70 activity. Cell 74: 5-6.

Simmons, D. 1986. DNA-binding region of the simian virus 40 tumor antigen. J. Virol. 57: 776-785.

Smale, S.T. and R. Tjian. 1986. T antigen-DNA polymerase a complex implicated in SV40 DNA replication. Mol. Cell. Biol. 6: 4077-4087.

Srinivasan, A., K. Peden, and J.M. Pipas. 1989. The large tumor antigen of simian virus 40 encodes at least two distinct transforming functions. J. Virol. 63: 5459-5463.

Stahl, H., P. Droge, and R. Knippers. 1986. DNA helicase activity of SV40 large tumor antigen. EMBO I. 5: 1939-1944.

Stillman, B. 1989. Initiation of eukaryotic DNA replication in vitro. Annu. Rev. Cell Biol. 5: 197-245.

Stillman, B., R.D. Gerard, R.A. Guggenheimer, and Y. Gluzman. 1985. T antigen and template requirements for SV40 DNA replication in vitro. EMBO I. 4: 2933-2939.

Stubdal, H., J. Zalvide, and J.A. DeCaprio. 1996. Simian virus 40 large $\mathrm{T}$ antigen alters the phosphorylation state of the RBrelated proteins p130 and p107. J. Virol. 70: 2781-2788

Symonds, H.S., S.A. McCarthy, J. Chen, J.M. Pipas, and T. Van Dyke. 1993. Use of transgenic mice reveals cell-specific transformation by a simian virus $40 \mathrm{~T}$-antigen amino-terminal mutant. Mol. Cell. Biol. 13: 3255-3265.

Szyperski, T., M. Pellecchia, D. Wall, C. Georgopoulos, and K. Wuthrich. 1994. NMR structure determination of the Escherichia coli DnaJ molecular chaperone: Secondary structure and backbone fold of the amino-terminal region (residues 2-108) containing the highly conserved J domain. Proc. Natl. Acad. Sci. 91: 11343-11347.

Thompson, D.L., D. Kalderon, A.E. Smith, and M.J. Tevethia.
1990. Dissociation of $\mathrm{Rb}$ binding and anchorage-independent growth from immortalization and tumorigenicity using SV40 mutants producing amino-terminally truncated large $\mathrm{T}$ antigens. Virology 178: 15-34.

Towbin, H., T. Staehelin, and J. Gordon. 1979. Electrophoretic transfer of proteins from polyacrylamide gels to nitrocellulose sheets: Procedure and some applications. Proc. Natl. Acad. Sci. 76: 4350-4354.

Tsai, J. and M.G. Douglas. 1996. A conserved HPD sequence of the J-domain is necessary for YDJ1 stimulation of Hsp70 ATPase activity at a site distinct from substrate binding. $J$. Biol. Chem. 271: 9347-9354.

Virshup, D.M., M.G. Kauffman, and T.J. Kelly. 1989. Activation of SV40 DNA replication in vitro by cellular protein phosphatase 2A. EMBO I. 8: 3891-3898.

Virshup, D.M., A.A.R. Russo, and T.J. Kelly. 1992. Mechanism of activation of simian virus 40 DNA replication by protein phosphatase 2A. Mol. Cell. Biol. 12: 4883-4895.

Waga, S. and B. Stillman. 1994. Reconstitution of DNA replication. Nature 369: 207.

Wall, D., M. Zylicz, and C. Georgopoulos. 1994. The NH2-terminal 108 amino acids of the Escherichia coli DnaJ protein stimulate the ATPase activity of DnaK and are sufficient for lambda replication. J. Biol. Chem. 269: 5446-5451.

-1995. The conserved G/F motif of the Dnal chaperone is necessary for the activation of the substrate binding properties of the DnaK chaperone. I. Biol. Chem. 270: 2139-2144.

Weisshart, K., M.K. Bradley, B.M. Weiner, C. Schneider, I. Moarefi, E. Fanning, and A.K. Arthur. 1996. An amino-terminal deletion mutant of simian virus 40 (SV40) large $\mathrm{T}$ antigen oligomerizes incorrectly on SV40 DNA but retains the ability to bind to DNA polymerase $\alpha$ and replicate SV40 DNA in vitro. J. Virol. 70: 3509-3516.

Wessel, R., J. Schweizer, and H. Stahl. 1992. Simian virus 40 $\mathrm{T}$-antigen DNA helicase is a hexamer which forms a binary complex during biderectional unwinding from the viral origin of DNA replication. J. Virol. 66: 804-815.

Wiekowski, M., P. Droge, and H. Stahl. 1987. Monoclonal antibodies as probes for a function of large $\mathrm{T}$ antigen during the elongation process of simian virus 40 DNA replication. $J$. Virol. 61: 411-418.

Wild, J., E. Altman, T. Yura, and C.A. Gross. 1992. DnaK and Dnal heat shock proteins participate in protein export in Escherichia coli. Genes \& Dev. 6: 1165-1172.

Wobbe, C.R., F.B. Dean, L. Weissbach, and J. Hurwitz. 1985. In vitro replication of duplex circular DNA containing the simian virus 40 DNA origin site. Proc. Natl. Acad. Sci. 82: 57105714.

Yaglom, J., A.L. Goldberg, D. Finley, and M. Sherman. 1996. The molecular chaperone Ydj1 is required for p34cdc28-dependent phosphorylation of Cln 3 that signals its degradation. Mol. Cell. Biol. 16: 3679-3684.

Zalvide, J. and J.A. DeCaprio. 1995. Role of pRb-related proteins in simian virus 40 large-T-antigen-mediated transformation. Mol. Cell. Biol. 15: 5800-5810.

Zhu, J.Y., P.W. Rice, M. Chamberlain, and C.N. Cole. 1991. Mapping the transcriptional transactivation function of simian virus 40 large T antigen. J. Virol. 65: 2778-2790.

Zhu, J., P.W. Rice, L. Gorsch, M. Abate, and C.N. Cole. 1992. Transformation of a continuous rat embryo fibroblast cell line requires three separate domains of simian virus 40 large T antigen. I. Virol. 66: 2780-2791.

Zylicz, M., D. Ang, K. Liberek, and C. Georgopoulos. 1989. Initiation of lambda DNA replication with purified host- and bacteriophage-encoded proteins: the role of the dnaK, dnaJ and grpE heat shock proteins. $E M B O$ J. 8: 1601-1608. 


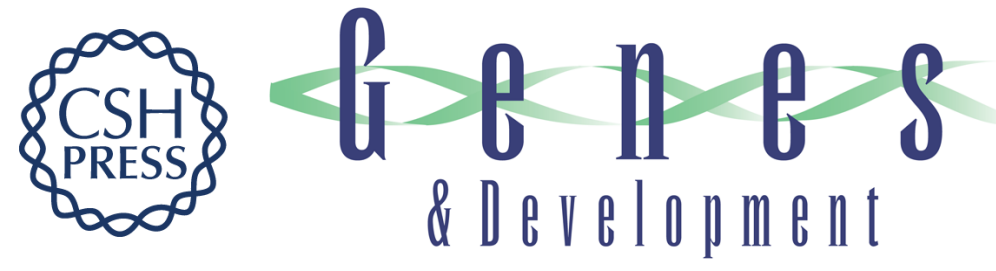

\section{DnaJ/hsp40 chaperone domain of SV40 large T antigen promotes efficient viral DNA replication.}

K S Campbell, K P Mullane, I A Aksoy, et al.

Genes Dev. 1997, 11:

Access the most recent version at doi:10.1101/gad.11.9.1098

References This article cites 83 articles, 51 of which can be accessed free at:

http://genesdev.cshlp.org/content/11/9/1098.full.html\#ref-list-1

License

Email Alerting

Service

Receive free email alerts when new articles cite this article - sign up in the box at the top right corner of the article or click here.

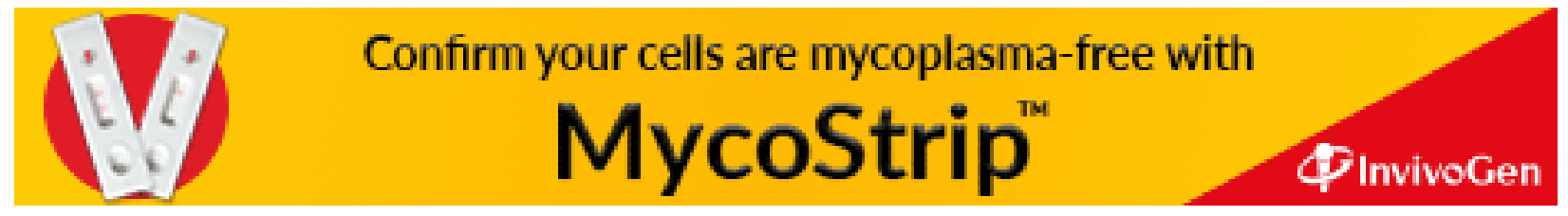

